\title{
Evaluation of therapy management and outcome in Takotsubo syndrome
}

\author{
Nadine Abanador-Kamper ${ }^{1,2^{*}}$ D, Lars Kamper ${ }^{2,3 \dagger}$, Judith Wolfertz ${ }^{1,2}$, Witali Pomjanski ${ }^{1,2}$, Anamaria Wolf-Pütz ${ }^{4}$ \\ and Melchior Seyfarth ${ }^{1,2}$
}

\begin{abstract}
Background: To date there is no validated evidence for standardized treatment of patients with Takotsubo syndrome (TTS). Medication therapy after final TTS diagnosis remains unclear. Previous data on patient outcome is ambivalent. Aim of this study was to evaluate medication therapy in TTS and to analyze patient outcome.

Methods: Within an observational retrospective cohort study we analyzed our medical records and included 72 patients with TTS that underwent cardiovascular magnetic resonance imaging (CMR) after a median of 2 days interquartile range (IQR 1-3.5). We investigated medication therapy at discharge. Medication implementation and major adverse clinical events (MACE) were prospectively evaluated after a median follow-up of 24 months (IQR 6-43). Left ventricular function, myocardial oedema and late gadolinium enhancement were analyzed in a CMR follow-up if available.
\end{abstract}

Results: Antithrombotic therapy was recommended in 69 (96\%) patients including different combinations. Antiplatelet monotherapy was prescribed in 28 (39\%) patients. Dual antiplatelet therapy was recommended in 29 (40\%) patients. Length of therapy duration varied from one to twelve months. Only in one case oral anticoagulation was prescribed due to apical ballooning with a left ventricular ejection fraction $<30 \%$. In all other cases oral anticoagulation was recommended due to other indications. B-adrenoceptor antagonists and ACE inhibitors were recommended in 63 (88\%), mineralocorticoid receptor antagonists were prescribed in 31 (43\%) patients. After a median of 2 months (IQR 1.3-2.9) left ventricular function significantly recovered $(49.1 \% \pm 10.1$ vs. $64.1 \% \pm 5.7, P<0.001)$ and myocardial oedema significantly decreased $(13.5 \pm 11.3$ vs. $0.6 \% \pm 2.4, P=<0.001)$ in the CMR follow-up. The 30-day mortality was $1 \%$. MACE rate after 24 months was $12 \%$.

Conclusion: Although therapy guidelines for TTS currently do not exist, we found that the majority of patients were treated with antithrombotic and heart failure therapy for up to twelve months. Left ventricular function and myocardial oedema recovered rapidly within the first two months. Outcome analysis showed a low bleeding rate and a high short-term survival. Therefore, TTS patients might benefit from antithrombotic and heart failure therapy at least for the first two months.

Keywords: Takotsubo cardiomyopathy, Acute coronary syndrome, Cardiovascular magnetic resonance imaging, Antiplatelet therapy, Antithrombotic management, Prognosis

\section{Background}

Takotsubo syndrome (TTS) is a form of acute mostly reversible heart failure syndrome. It was first described in Japan. Since that several international reports and mostly observational studies have been described [1]. Early distinguishing from acute myocardial infarction is

\footnotetext{
* Correspondence: nadine.abanador@helios-kliniken.de

†Equal contributors

'Department of Cardiology, HELIOS Medical Center Wuppertal, University Hospital Witten/Herdecke, Arrenberger Str. 20, 42117 Wuppertal, Germany ${ }^{2}$ Center for Clinical Medicine Witten/Herdecke University Faculty of Health, Wuppertal, Germany

Full list of author information is available at the end of the article
}

challenging and its final diagnosis remains unclear in the early stage. In the majority of patients coronary angiogram is inconspicuous; however coexistence of coronary artery disease in TTS is described [2,3]. Cardiac imaging plays a major role in the diagnosis of TTS and reveals important findings on left ventricular dysfunction. Cardiovascular magnetic resonance imaging (CMR) has a high diagnostic value in patients with TTS [4]. The pathophysiology of TTS seems to be complex, yet there is no current proven pathophysiological mechanism. A stress-induced catecholamine release with impact on the 
cardiovascular system plays a major role [5-7]. Pathophysiological hypotheses include vascular and myocardial mechanisms that lead to the phenotype of TTS. Blood hyperviscosity caused by vascular dysfunction was found to have an impact [8]. However, intracoronary thrombosis or plaque rupture seems not to be present in TTS [9]. Considering existing data on pathophysiology of TTS patients might benefit from therapy of vascular and acute heart failure. To date no evidence exists for medication treatment and treatment duration of these patients, since there is a lack on randomized clinical trials. In particular, there is no evidence on antithrombotic therapy. All patients initially receive dual antiplatelet therapy on the basis of suspected myocardial infarction. However, there is no recommendation of antithrombotic medication after final diagnosis of TTS. Currently, data are limited on how TTS patients are treated with antiplatelet therapy after discharge. Aim of this study was to evaluate pharmacological treatment and therapy recommendations in TTS and to analyze patient outcome.

\section{Methods}

\section{Study design}

We retrospectively analyzed the data files of our tertiary care university hospital between 2005 and 2017 for all patients that presented with acute chest pain, elevated cardiac biomarkers, new electrocardiography abnormalities and lack of a target lesion in the angiogram that underwent CMR during the index event $(<30$ days after admission). Based on the current ESC position statement and the Mayo Clinic diagnostic criteria $[10,11]$ on
TTS diagnosis was established in cases with acute chest pain, transient, acute heart failure with or without apical ballooning or wall motion abnormalities that extended beyond a single epicardial vascular distribution and absence of late gadolinium enhancement (LGE) in CMR. We included 72 patients with TTS (Fig. 1). All patients received standard therapy for acute coronary syndrome according to the current guidelines. All patients $<18$ years, or with other diagnoses than TTS, a prior history of myocardial infarction, coronary bypass surgery, congenital heart disease and contraindications to CMR and CMR contrast agents were excluded. The local ethics committee approved this study. Patients were contacted directly via telephone and study enrollment was verified. Patients gave written informed consent.

\section{Laboratory parameters}

Blood samples were taken as a part of a standardized routine at the time of hospital admission to measure high-sensitivity troponin $\mathrm{T}$, creatine-kinase myocardialband (CK-MB) and creatine-kinase (CK)-values daily until normalization. Plasma samples for C-reactive protein (CRP) - and glomerular filtration rate (GFR)-values were evaluated. Peak values of high-sensitivity troponin T, CK$\mathrm{MB}, \mathrm{CK}, \mathrm{CRP}$ and lowest value of GFR were acquired.

\section{Medication treatment}

Medication at discharge including antiplatelet therapy, anticoagulation, $B$-adrenoceptor antagonists (BB), angiotensin converting enzyme receptor inhibitors (ACEi), angiotensin receptor blockers (ARB), mineralocorticoid receptor antagonists (MRA) and their temporal

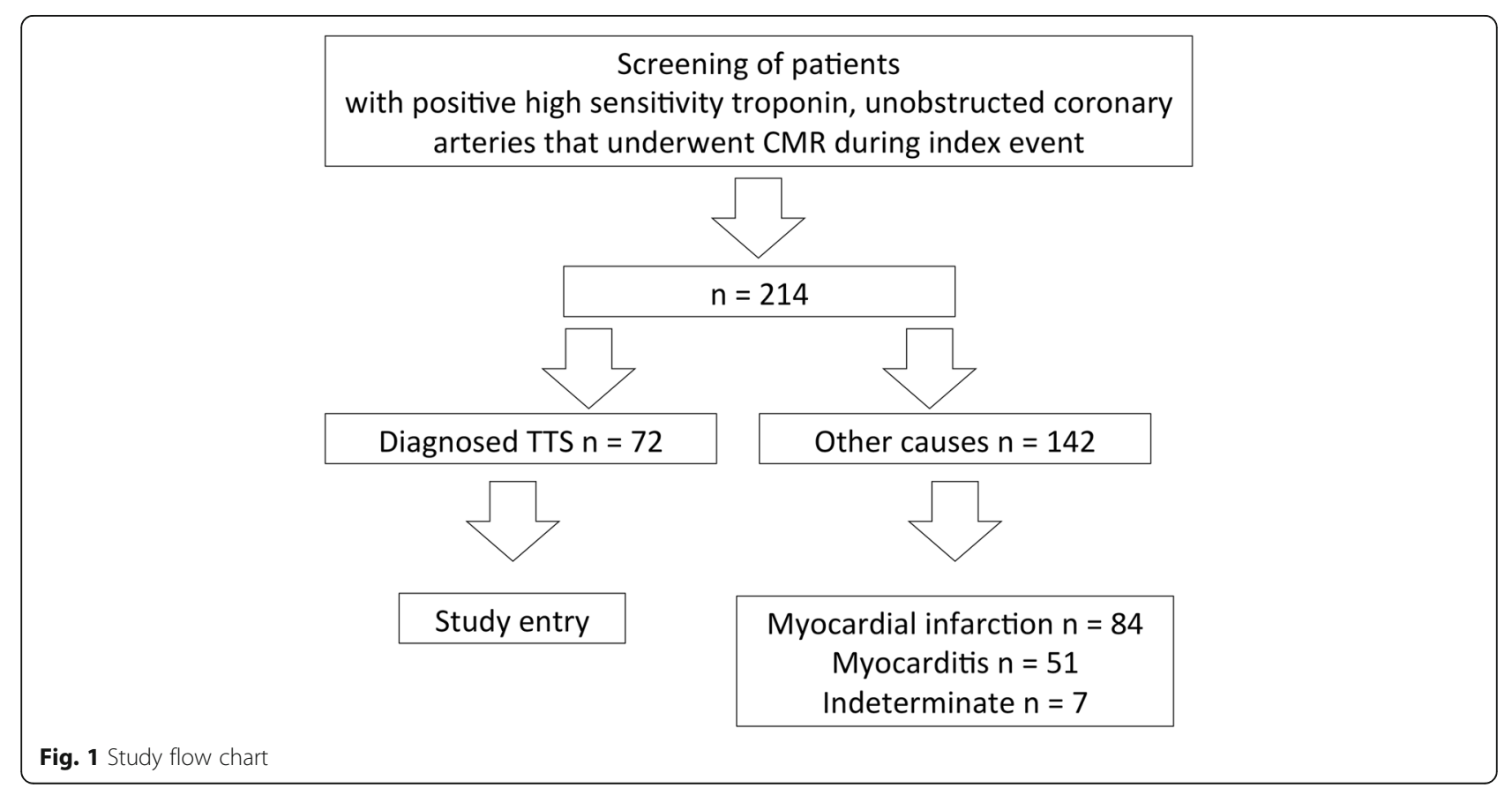


recommendation was evaluated. Implementation of medication was analysed for each patient via standardized questionnaire by telephone contact either with the patient or treating physician.

\section{CMR protocol and image analysis}

All CMR scans were performed on a 1.5-Tesla scanner (Intera Achieva; Philips; Best, Netherlands). CMR studies were independently reviewed by two ESC Level III cardiologists. CMR protocol included analysis of left ventricular function, wall motion analysis, myocardial oedema assessment and LGE. Left ventricular function was assessed by a standard steadystate free precession technique (2D turbo gradient echo sequence) in short, four-chamber, two-chamber and three-chamber views of the left ventricle. As previously validated, T2-weighted black blood turbo-spin-echo sequences (with and without fat saturation pre-pulse) in short axis and in four chamber view covering the complete left ventricle were performed to evaluate myocardial or pericardial oedema [12-16].

LGE images of the left and right ventricles were acquired $10 \mathrm{~min}$ after injection of $0,2 \mathrm{mmol} / \mathrm{kg}$ of gadoteridol (Prohance ${ }^{\circ}$, Bracco-Imaging, Konstanz, Germany). A three-dimensional inversion-recovery turbo gradient echo sequence was used for image acquisition covering the entire left and right ventricle in multiple slices without gap in the short axis, four-, two- and three-chamber long axis views.

CMR parameters were analysed by the use of a specific software-tool (Extended MR Workspace 2.6.3.4, Philips Medical Systems, Best, Netherlands and CMR 42, Version 4.0, Circle Cardiovascular Imaging Inc., Calgary, Canada). Left ventricular ejection fraction (LV-EF) and left ventricular parameters were calculated by assessment of the volumes of the endocardial contours in diastole and systole of the four- and two-chamber slices. Typical wall motion abnormalities were defined as apical, midventricular or basal ballooning of the left ventricle. For the calculation of left ventricular mass endocardial and epicardial contours were drawn manually in the short axis of the left ventricle. Quantitative analysis of myocardial oedema was described as $>2 \mathrm{SD}$ signal intensity threshold from remote normal myocardium [16]. Myocardial oedema volumes were expressed as percentage of the total LV mass.

LGE was determined by semi-automated quantification in each short axis slice. LGE was defined as hyperenhanced area with signal intensity threshold $\geq 5 \mathrm{SD}$ above a region of interest of normal "nulled" myocardium [17]. LGE size was expressed as percentage of LV volume given by the sum of the volume of LGE regions for all slices divided by the sum of the total LV myocardial volume.

\section{CMR follow-up and major adverse clinical events}

Patients were screened for CMR follow-up and left ventricular functional parameters were analyzed. Major adverse clinical events (MACE) at follow-up were evaluated via standard questionnaire by telephone contact with the patient or the treating physician after 24 months. Events were verified by hospital charts. MACE was defined as recurrence of TTS or myocardial infarction, stroke or death. The diagnosis of myocardial infarction was based on acute chest pain, pathologically elevated plasma levels for high-sensitivity troponin I, CK-MB and CK, ST-segment elevation of at least $0.1 \mathrm{mV}$ in $\geq 2$ extremity leads or at least $0.2 \mathrm{mV}$ in $\geq 2$ precordial leads and an identifiable target lesion in the angiogram.

\section{Statistical analysis}

Categorical variables are described by frequencies; continuous data are expressed as median with interquartile range or with mean and standard deviation. Wilcoxon matched-pairs signed-ranks test was used to test whether distribution of initial and follow-up CMR parameters differed. We used the Kaplan-Meier method to examine the proportion of patients with events and to estimate the probability of events for different timings. A two-sided $P$ value of less than 0.05 was considered to indicate statistical significance. All statistical analysis was performed using STATA/IC 14.2 software (Stat Corp, LP, Texas, USA).

\section{Results}

\section{Demographic and laboratory findings}

Mean age of the patients was $68.8 \pm 17.5$ years with 67 (93\%) female patients. An underlying stress trigger was reported in $36(50 \%)$ patients and prehospital resuscitation in three (4\%) patients. In one patient an underlying pheochromocytoma was diagnosed two years after the Takotsubo event. A treated depression was observed in eleven (15\%) patients, an epilepsy in one patient. Cardiovascular risk factors included arterial hypertension in 49 (68\%) patients, Diabetes mellitus in $7(10 \%)$ patients, current smoking in $9(12 \%)$ patients, hyperlipidemia in $20(28 \%)$ patients and family history for myocardial infarction in $16(22 \%)$ patients. Median body mass index was 24 (IQR 22-29). Median peak value of highsensitivity troponin $\mathrm{T}$ was $371.0 \mathrm{pg} / \mathrm{ml}$ (IQR 172-583), of CK-MB 34.0 U/l (IQR 23-47), of CK 188.0 U/l (IQR 137-338) and of CRP $1.20 \mathrm{mg} / \mathrm{dl}$ (IQR 0-3). CRP value was obtained for 60 patients $(83 \%)$. The median lowest GFR-level was $68.0 \mathrm{ml} / \mathrm{min} / 1.73$ (IQR 58-80).

\section{Medication treatment and temporal recommendation}

General therapy recommendation of the study population is given in Table 1. All patients received medication 
Table 1 Recommended therapy management after index event

\begin{tabular}{|c|c|}
\hline & Study population $n=72$ \\
\hline \multicolumn{2}{|l|}{ Therapy recommendation } \\
\hline ASA & 59 (81.9\%) \\
\hline Clopidogrel & $28(38.8 \%)$ \\
\hline Prasugrel & $2(2.8 \%)$ \\
\hline Ticagrelor & $4(5.6 \%)$ \\
\hline OAC & $12(16.6 \%)$ \\
\hline LWMH once per day & $1(1.4 \%)$ \\
\hline Statin & $47(65.3 \%)$ \\
\hline Beta-blocker & $63(87.5 \%)$ \\
\hline ACE inhibitor/AT inhibitor & $63(87.5 \%)$ \\
\hline Mineralocorticoid receptor antagonist & $31(43.1 \%)$ \\
\hline \multicolumn{2}{|l|}{ Duration of antithrombotic therapy } \\
\hline No recommendation & $41(56.9 \%)$ \\
\hline With recommendation: & $29(40.3 \%)$ \\
\hline 1 month & $4(5.6 \%)$ \\
\hline 3 months & $8(11.1 \%)$ \\
\hline 6 months & $6(8.3 \%)$ \\
\hline 12 months & $11(15.3 \%)$ \\
\hline \multicolumn{2}{|l|}{ Reason for OAC } \\
\hline Atrial fibrillation & $10(13.8 \%)$ \\
\hline Heart failure & $1(1.4 \%)$ \\
\hline Deep vein thrombosis & $1(1.4 \%)$ \\
\hline
\end{tabular}

Data is presented as number of patients and percentage $\angle W M H$ low weight molecular heparin, OAC oral anticoagulation Antithrombotic therapy includes antiplatelet mono- or dual therapy or oral anticoagulation

therapy. Antithrombotic therapy was recommended in 69 (96\%) patients including different combinations of Acetylsalicyl-acid (ASA), P2Y12 antagonists, oral anticoagulation (OAC) and low molecular weight heparin. Out of twelve patients with $\mathrm{OAC}$ in one patient the indication was due to new onset of apical ballooning with a left ventricular ejection fraction (LV-EF) $<30 \%$. In ten (14\%) patients the indication was a history of atrial fibrillation and in one patient a history of deep vein thrombosis. Heart failure medication as $\mathrm{BB}$ and $\mathrm{ACEi} / \mathrm{ARB}$ was recommended in $63(88 \%)$ patients. MRA was prescribed in 31 (43\%) patients.

The different antithrombotic therapy strategies are presented in Table 2 . In nine $(4 \%)$ patients no antiplatelet therapy was prescribed, out of these, six patients had an OAC due to history of atrial fibrillation. An OAC in combination with ASA without temporal recommendation or Clopidogrel for three months was recommended in four $(6 \%)$ patients.

Mono- and dual antiplatelet therapy was the majority of therapy recommendations. In 25 (35\%) patients ASA monotherapy was advised, out of these only one patient
Table 2 Recommended therapy management after index event

\begin{tabular}{|c|c|}
\hline & Study population $n=72$ \\
\hline No antiplatelet therapy & $9(4.2 \%)$ \\
\hline With OAC monotherapy & 6 \\
\hline$O A C+A S A$ & $3(4.2 \%)$ \\
\hline \multicolumn{2}{|l|}{ Without temporal recommendation } \\
\hline OAC + Clopidogrel & $1(1.4 \%)$ \\
\hline \multicolumn{2}{|l|}{$\begin{array}{l}\text { With temporal recommendation } \\
\text { for } 3 \text { months }\end{array}$} \\
\hline Monotherapy antiplatelet: & $28(38.9 \%)$ \\
\hline ASA & $25(34.7 \%)$ \\
\hline Without temporal recommendation & 24 \\
\hline $\begin{array}{l}\text { With temporal recommendation } \\
\text { for } 3 \text { months }\end{array}$ & 1 \\
\hline Clopidogrel & $2(2.8 \%)$ \\
\hline Without temporal recommendation & 1 \\
\hline $\begin{array}{l}\text { With temporal recommendation } \\
\text { for } 6 \text { months }\end{array}$ & 1 \\
\hline Ticagrelor & $1(1.4 \%)$ \\
\hline $\begin{array}{l}\text { With temporal recommendation } \\
\text { for } 12 \text { months }\end{array}$ & 1 \\
\hline Dual antiplatelet therapy: & $29(40.3 \%)$ \\
\hline ASA + Clopidogrel & $24(33.3 \%)$ \\
\hline Without temporal recommendation & 5 \\
\hline With temporal recommendation: & 19 \\
\hline 1 month & 2 \\
\hline 3 months & 4 \\
\hline 6 months & 4 \\
\hline 12 months & 8 \\
\hline ASA + Prasugrel & $2(2.8 \%)$ \\
\hline Without temporal recommendation & 1 \\
\hline $\begin{array}{l}\text { With temporal recommendation } \\
\text { for } 12 \text { months }\end{array}$ & 1 \\
\hline ASA + Ticagrelor & $3(4.2 \%)$ \\
\hline Without temporal recommendation & 0 \\
\hline With temporal recommendation & 3 \\
\hline 1 month & 1 \\
\hline 3 months & 1 \\
\hline 12 months & 1 \\
\hline "Triple" therapy with ASA & $2(2.8 \%)$ \\
\hline $\begin{array}{l}1 \text { month, Clopidogrel + OAC } 6 \text { months, } \\
\text { OAC monotherapy }\end{array}$ & 1 \\
\hline $\begin{array}{l}1 \text { month, Clopidogrel + OAK } 12 \text { months, } \\
\text { OAC monotherapy }\end{array}$ & 1 \\
\hline
\end{tabular}

Data is presented as number of patients and percentage ASA Acetylsalicyl Acid, LWMH low weight molecular heparin, OAC oral anticoagulation 
was given a temporal recommendation for three months. Dual antiplatelet therapy was recommended in 29 (40\%) patients with a combination of ASA and Clopidogrel in $24(33 \%)$ patients. In fewer patients dual antiplatelet therapy included the combination of ASA and Clopidogrel or ASA and Ticagrelor, mostly with a temporal recommendation ranging from one to twelve months. Triple therapy was recommended in two patients with a temporal strategy in both patients. Both recommendations of duration differed in length of OAC and Clopidogrel. Duration of antithrombotic therapy was given in 29 (40\%) with the longest recommendation for 12 months.

\section{Implementation of prescribed antithrombotic therapy}

Evaluation of prescribed antithrombotic therapy revealed that out of these 29 patients 19 (66\%) patients completed the recommended duration. Two patients received a longer treatment due to unawareness of patients or physician. Therapy was aborted earlier in eight (28\%) patients secondary to ASA intolerance in three patients and rejection of ASA therapy in three other patients. Gastrointestinal bleeding or malignancy was reported in two patients. The treating physician initiated antiplatelet monotherapy by himself in two patients due to diagnosis of TTS.

\section{CMR parameters and CMR follow-up}

Initial CMR scan was performed after a median of 2 days (IQR1-3.5) during index event in all included patients (Table 3). All patients had a lack of LGE. Mean size of myocardial oedema was measured with $13.5 \% \pm 11.3$. In seven $(10 \%)$ patients a typical wall motion abnormality was not observed in the initial CMR, however, myocardial oedema was significant and typical in all of these patients. CMR follow-up scan was performed in 63 (88\%) patients after a median of 2.3 months (IQR 1.3-2.9). Mean LV-EF significantly increased between both scans $(49.1 \% \pm 10.1$ vs. $64.1 \% \pm 5.7, P<0.001)$. Furthermore

Table 3 Description of differences between CMR parameters of initial CMR and follow-up CMR scan

\begin{tabular}{lllr}
\hline CMR parameters & & & \\
& CMR I $n=72$ & CMR II $n=63$ (88\%) & $p$-value* \\
\hline LV-EF (\%) & $49.1 \pm 10.1$ & $64.1 \pm 5.7$ & $<0.001$ \\
LV-EDVI (ml/m²) & $76.2 \pm 13.7$ & $72.1 \pm 13.9$ & 0.198 \\
T2 Volume (\%) & $13.5 \pm 11.3$ & $0.6 \pm 2.4$ & $<0.001$ \\
LGE Volume (\%) & $0.0 \pm 0.0$ & $0.0 \pm 0.0$ & \\
$\Delta$ angiogram-CMR (d) & $2(1-3.5)$ & & \\
$\Delta$ CMR I-CMR II (months) & $2.3(1.3-2.9)$ & &
\end{tabular}

LVEF, LVEDVI, LGE and T2 volumes are presented as mean and standard deviation. $\Delta$ angiogram-to-CMR, $\triangle \mathrm{CMR}$ I-to-CMRII are presented as median with interquartile range

$C M R$ Cardiac magnetic resonance, $L V-E F$ left ventricular ejection fraction, $L V$-EDVI left ventricular end diastolic volume index, LGE late gadolinium enhancement

*Wilcoxon matched-pairs signed rank test myocardial oedema significantly decreased in the followup scan $(13.5 \% \pm 11.3$ vs. $0.6 \% \pm 2.4, P<0.001)$.

\section{MACE and Clinical follow-up analysis}

All 72 patients were evaluated for follow-up after a median of 24 months (IQR 6-43). We observed 9 (12\%) events in the study population of which four occurred in-hospital within 30 days after TTS. In-hospital mortality was $1 \%$. Three patients died from non-cardiac events (malignancy) under the medication of dual or mono antiplatelet therapy. Long-term follow up of patients revealed an estimated mortality rate of $5 \%$ after two years and $8 \%$ after three years including deaths of any cause (Fig. 2 and Table 4). In two patients stroke occurred in the first 30 days with a left ventricular thrombus in one patient. None of these patients received prior oral anticoagulation, but antiplatelet therapy. Another patient had a stroke event twelve months after TTS under oral anticoagulation due to atrial fibrillation. One patient suffered from recurrent TTS twelve months after the first event under dual antiplatelet therapy, BB and ACEi. In one patient we observed myocardial infarction under antiplatelet monotherapy (Table 5).

\section{Discussion}

To date this is the first study focusing on the evaluation of therapy management in relation to outcome after TTS. Main findings of our study were that patients with TTS receive antithrombotic therapy in most cases with a maximal duration of twelve months. Combination of antiplatelet therapy, oral anticoagulation and duration varied brightly. Dual antiplatelet therapy with a specific duration was highly recommended at discharge. Implementation rate was high and bleeding rate was low. Heart failure medication with $\mathrm{BB}$ and $\mathrm{ACEi}$ at discharge was found in the majority of patients. Left ventricular function and myocardial oedema improved after two

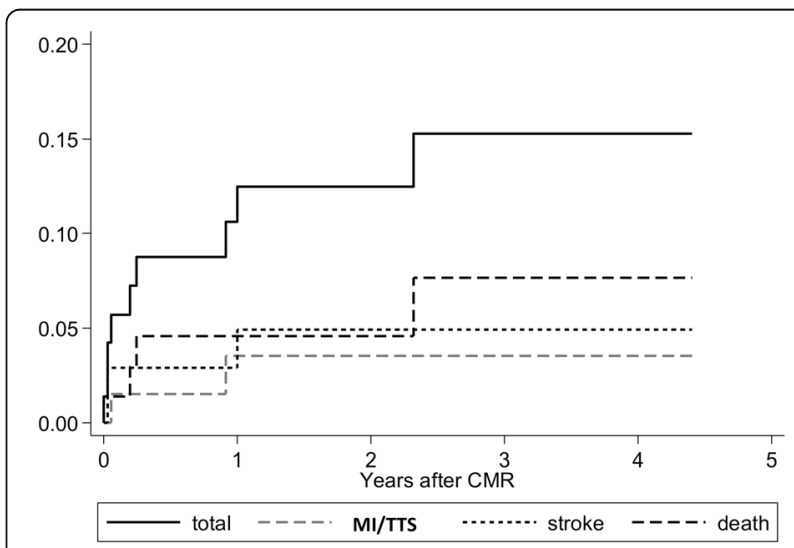

Fig. 2 Kaplan-Meier graph of events showing the proportion of major adverse clinical events 
Table 4 Description of MACE

\begin{tabular}{|c|c|c|c|}
\hline \multicolumn{4}{|c|}{ Kaplan-Meier estimation } \\
\hline \multirow[b]{2}{*}{ MACE } & & $\begin{array}{l}\text { estimated rate (95\%-confidence } \\
\text { interval) }\end{array}$ & \\
\hline & & 24 months & 36 months \\
\hline Total events & $9(12 \%)$ & $12.5(6.4-23.5)$ & $15.3(8.0-28.0)$ \\
\hline Death & $4(5.6 \%)$ & $4.6(1.5-13.5)$ & $7.6(2.8-20.3)$ \\
\hline Stroke & $3(4.2 \%)$ & $4.9(1.6-14.7)$ & $4.9(1.6-14.7)$ \\
\hline $\mathrm{MI} / \mathrm{TTS}$ & $2(2.8 \%)$ & $3.5(0.9-13.6)$ & $3.5(0.9-13.6)$ \\
\hline
\end{tabular}

Data is presented as number of patients and percentage. Estimated event rates are presented with Kaplan-Meier estimation after 24 and 36 months MACE major adverse clinical events, $M I$ myocardial infarction, $T T S$ Takotsubo syndrome

months. MACE rate was moderate with an event rate of $12 \%$ and a 30 -days mortality rate of $1 \%$.

\section{Clinical findings and emotional triggers}

Our clinical findings, such as the female emphasized distribution in TTS patients, the coexisting neurologic or psychiatric disorders and evaluation of emotional triggers is in line with previous studies [1, 18-21].

\section{Antiplatelet therapy}

Previous studies indicate that blood hyperviscosity is a part of pathophysiology in TTS. Blood viscosity, erythrocyte membranes and endothelial integrity were altered in patients with previous TTS that were exposed to sympathetic stimulation matched to a control group with chest pain and without coronary artery disease [8]. A significant increase of endothelial dysfunction was found in another study on 22 TTS patients matched to a control group [22]. Interestingly, there was no difference in these patients regarding arterial stiffness and intimamedia thickness. However, intracoronary thrombosis and plaque rupture were not observed in TTS by an intracoronary ultrasound study [9]. These findings underline that vascular and endothelial dysfunction plays a role in the pathophysiology of TTS and that patients might benefit from antiplatelet therapy. In our study we have found that the majority of patients received antiplatelet therapy after discharge. Recommendations were implemented in the majority of patients. Bleeding rate after antithrombotic therapy was low. The medication with antiplatelet therapy might have a beneficial effect. This might be one explanation why MACE rates and mortality in our study was relatively low compared to previous register data [1, 23]. In our subgroup analysis we observed slightly higher stroke rates within the first 30 days compared to previous reports. One explanation might be a potential formation of a left ventricular thrombus facilitated by apical ballooning and apical wall motion abnormalities. In our study, we observed one patient with left ventricular thrombus within the first 30 days after admission. Oral anticoagulation in the first 30 days might have a positive effect on decreasing stroke rates in TTS. Previous case series indicate that thrombus formation in TTS is rarely reported and that most thrombi were detected within the first 2 weeks, in some cases despite oral anticoagulation [24]. There is definitely a lack on large multicenter studies regarding the use and duration of antithrombotic medication, which needs further investigation to state a future guideline.

\section{Heart failure therapy and TTS recurrence}

Available data on the effect of $\mathrm{BB}$ on acute heart failure of TTS are ambivalent. In previous studies patients with intraventricular pressure gradients improved from intravenous application of $B B$ [25-27]. In a case series with left ventricular outflow tract (LVOT) obstruction in acute TTS treatment with BB decreased LVOT gradient within some days [28]. Some preclinical studies have shown a benefit in the use of $B B[29,30]$. One possible explanation for the ineffectiveness of $\mathrm{BB}$ that is currently discussed is involvement of $ß 2$-receptors in TTS, rather than $ß 1$-adrenoceptor stimulation. However, a metaanalysis on the efficacy of medical treatment of TTS patients [26] did not reveal a positive effect of $\mathrm{BB}, \mathrm{ACEi} /$ $A R B$ and statins on the recurrence rate of TTS. In a large cohort of patients Templin et al. [1] revealed that the use of ACEi/ARB were associated with improved survival at 1 year. The authors discussed a reduction in

Table 5 Description of MACE depending on prior antithrombotic therapy

\begin{tabular}{|c|c|c|c|c|c|c|}
\hline & & & & & & Study population $n=72$ \\
\hline MACE & No AT $n=3$ & AT $n=28$ & Dual AT $n=29$ & $\mathrm{OAC} n=6$ & $\mathrm{AT}+\mathrm{OAC} n=4$ & Triple therapy $n=2$ \\
\hline No event & $2(3 \%)$ & $25(35 \%)$ & $25(35 \%)$ & $5(7 \%)$ & $4(6 \%)$ & $2(3 \%)$ \\
\hline With Event & $1(1 \%)$ & $3(4 \%)$ & $4(6 \%)$ & $1(1 \%)$ & 0 & 0 \\
\hline Myocardial infarction & 0 & $1(1 \%)$ & 0 & 0 & 0 & 0 \\
\hline Stroke & 0 & $1(1 \%)$ & $1(1 \%)$ & $1(1 \%)$ & 0 & 0 \\
\hline Recurrence of TTS & 0 & 0 & $1(1 \%)$ & 0 & 0 & 0 \\
\hline Death & $1(1 \%)$ & $1(1 \%)$ & $2(3 \%)$ & 0 & 0 & 0 \\
\hline
\end{tabular}

Data is presented as number of patients and percentage

$M A C E$ major adverse cardiac event, $A T$ antiplatelet therapy, $O A C$ anticoagulation therapy 
sympathetic activity or anti-inflammatory effects of ACEi on myocardium that might explain the reduction in recurrence rate. However BB did not show any benefit at 1 year in the same study. Furthermore, use and prescription of antiplatelet therapy was not analyzed in that study. In our study 30 -days mortality was also low. The majority of patients in our study were treated with $\mathrm{BB}$ and ACEi. If low mortality rate is caused by the medication with $\mathrm{BB}$ and ACEi medication or by antithrombotic medication or the combination of both has to be investigated in further studies.

To date there is no evidence for prevention of TTS recurrence. Effects of $\mathrm{BB}$ and $\mathrm{ACEi} / \mathrm{ARB}$ on the prognosis of TTS patients still remain ambivalent. Overall, data on TTS recurrence is low, since cases described are rare. In our cohort we have found one patient with recurrent TTS. This patient was treated with BB and ACEi without recommendation of duration at discharge. The use of $\mathrm{BB}$ has been proposed to prevent TTS recurrence in some reports [25]. In a systematic review on incidence of TTS recurrence 31 cohorts (1664 TTS patients) were included [31]. Out of these 74 cases of recurrence after a mean follow-up of 24.5 months were described. Annual recurrence incidence was 1-2\%. Discharge medications included $\mathrm{BB}$ in $66.8 \%$, ACEi and ARB in $67.4 \%$. Recurrence rate correlated with $\mathrm{ACEi} / \mathrm{ARB}$ prescription was significantly lower. The recurrence rate in our study is in line with these data, however, further studies with larger cohorts need to prove this trend.

\section{MACE}

We observed a 30 -day mortality rate of $1 \%$ and an estimated mortality rate of $5 \%$ after two years including all causes of death. Prior data on long-term prognosis in TTS are ambivalent. Our analyses are in line with reports on a comparable mortality rate to an age- and gender matched population and to a large cohort study $[1,32]$. One explanation for the low mortality rate in our study might be that the majority of patients were treated with antithrombotic and heart failure medication. Redfors et al. described higher mortality rates, which can be compared to NSTEMI and STEMI patients. However, only $30 \%$ of these patients were treated with dual antiplatelet therapy and $45 \%$ of patients received BB [23]. Stroke rate in our study was $4 \%$ after two years, which is higher than previously reported $[1,23]$. Templin et al. described a stroke rate of $1.7 \%$ per patient-year [1]. In our study patients with acute stroke were treated with prior antiplatelet therapy. One hypothesis is that oral anticoagulation might have decreased these stroke events and should be considered until full recovery of left ventricular function. Currently, our investigation is the first study that has analyzed prognosis of TTS in regard to different antithrombotic therapy strategies.

\section{CMR}

In our cohort mean LV-EF during index event was $49.1 \% \pm 10.1$. After two months we found a complete recovery of LV-EF and a significant reduction of myocardial oedema in the majority of TTS patients. These findings are similar to previous reports [1]. First CMR studies on left ventricular function indicated a recovery in most patients after 6 months [4]. Further studies observed a faster recovery in the majority of patients [33-35]. Our data confirm that left ventricular function in TTS recovers rapidly. We therefore assume that medication used to treat heart failure is less effective after the first two months of TTS.

\section{Study limitation}

Due to the retrospective study design our analysis has following limitations: Not every patient was analyzed for a follow-up CMR, which compromises our CMR followup data. CMR was used as a major cardiac imaging tool for the diagnosis of TTS. Patients' number of Takotsubo cases over the years might be underestimated due to patients that could not be investigated through CMR because of contraindications to CMR or cardiogenic shock. Median time between angiogram and CMR was two days, which is already a rapid interval. However, previous literature has reported quick changes of left ventricular function within days or weeks. The few amounts of patients with normal LV-EF or lack of typical wall motion abnormalities in the initial CMR scan might be explained due to the fact that an interval of two days might not be short enough to represent all courses of TTS. Also we excluded patients with prior myocardial infarction to distinguish clearly TTS patients for this study. Patients with TTS and coexisting coronary artery disease might have different results and need further evaluation in future studies. Although we have performed an analysis on a relatively high number of TTS patients gained during a long period of time we achieved small numbers in the subgroup analysis regarding different antithrombotic therapy strategies. Conclusions that are drawn from the subgroup analysis have to be interpreted carefully and therefore, prospective multicenter studies need to be conducted to confirm our findings.

\section{Conclusions}

Currently, this is the first study analyzing prescribed therapy, therapy duration in TTS and prognosis depending on different therapy strategies. Although no therapy guidelines in TTS exist so far, the majority of patients in our study were treated with antithrombotic and heart failure therapy for a maximum of twelve months. Left ventricular function and myocardial oedema recovered rapidly within the first two months. Outcome analysis showed a low bleeding rate and a high short-term 
survival. Therefore, TTS patients might benefit from antithrombotic and heart failure therapy at least for the first two months. Further prospective studies need to be conducted to evaluate the optimal treatment strategy for TTS.

\section{Abbreviations}

ACEi: Angiotensin converting enzyme receptor inhibitors; ARB: Angiotensin receptor blockers; ASA: Acetylsalicyl-acid; BB: ß-adrenoceptor antagonists; CK: Creatine-kinase; CK-MB: Creatine-kinase myocardial band; CMR: Cardiovascular magnetic resonance imaging; CRP: C-reactive protein; GFR: Glomerular filtration rate; LGE: Late gadolinium enhancement; LV-EF: Left ventricular ejection fraction; MACE: Major adverse clinical events; MRA: Mineralocorticoid receptor antagonists; OAC: Oral anticoagulation; TTS: Takotsubo-Syndrome

\section{Acknowledgements}

We thank the staff of the cardiovascular magnetic imaging department of the HELIOS Medical Centre Wuppertal.

\section{Funding}

This study was supported by HELIOS Kliniken GmbH, [Grant ID 058848].

\section{Availability of data and materials}

Additional data is available from the corresponding author.

\section{Authors' contributions}

NAK and LK have contributed equally in concept of the study, data acquisition, and editing the manuscript. JW, WP, AWP and MS have contributed in concept of the study and critically revision of the manuscript. All authors have read and approved the manuscript and ensure that this is the case.

\section{Ethics approval and consent to participate}

The ethics committee of University Witten/Herdecke approved this study and patients gave written informed consent.

\section{Consent for publication}

Not applicable

\section{Competing interests}

The authors declare that they have no competing interests.

\section{Publisher's Note}

Springer Nature remains neutral with regard to jurisdictional claims in published maps and institutional affiliations.

\section{Author details}

'Department of Cardiology, HELIOS Medical Center Wuppertal, University Hospital Witten/Herdecke, Arrenberger Str. 20, 42117 Wuppertal, Germany. ${ }^{2}$ Center for Clinical Medicine Witten/Herdecke University Faculty of Health, Wuppertal, Germany. ${ }^{3}$ Department of Diagnostic and Interventional Radiology, HELIOS Medical Center Wuppertal, University Hospital Witten/ Herdecke, Wuppertal, Germany. ${ }^{4}$ Department of Cardiology, Augusta Hospital Düsseldorf, Academic Teaching Hospital of the University Faculty of Health, Düsseldorf, Germany.

Received: 10 July 2017 Accepted: 13 August 2017

Published online: 17 August 2017

\section{References}

1. Templin C, Ghadri J-R, Napp LC. Takotsubo (Stress) Cardiomyopathy. N Engl J Med. 2015;373:2689-91.

2. Gaibazzi N, Ugo F, Vignali L, Zoni A, Reverberi C, Gherli T. Tako-Tsubo cardiomyopathy with coronary artery stenosis: a case-series challenging the original definition. Int J Cardiol. 2009;133:205-12.

3. Previtali M, Repetto A, Panigada S, Camporotondo R, Tavazzi L. Left ventricular apical ballooning syndrome: prevalence, clinical characteristics and pathogenetic mechanisms in a European population. Int J Cardiol. 2009:134:91-6.

4. Eitel I, von Knobelsdorff-Brenkenhoff F, Bernhardt P, Carbone I, Muellerleile K, Aldrovandi $A$, et al. Clinical characteristics and cardiovascular magnetic resonance findings in stress (takotsubo) cardiomyopathy. JAMA. 2011;306:277-86.
5. Abraham J, Mudd JO, Kapur NK, Kapur N, Klein K, Champion HC, et al. Stress cardiomyopathy after intravenous administration of catecholamines and beta-receptor agonists. J Am Coll Cardiol. 2009;53:1320-5.

6. Kume T, Kawamoto T, Okura H, Toyota E, Neishi Y, Watanabe N, et al. Local release of catecholamines from the hearts of patients with tako-tsubo-like left ventricular dysfunction. Circ J. 2008;72:106-8.

7. Wittstein IS, Thiemann DR, Lima JAC, Baughman KL, Schulman SP, Gerstenblith $G$, et al. Neurohumoral features of myocardial stunning due to sudden emotional stress. N Engl J Med. 2005;352:539-48.

8. Cecchi E, Parodi G, Giglioli C, Passantino S, Bandinelli B, Liotta AA, et al. Stress-induced hyperviscosity in the pathophysiology of takotsubo cardiomyopathy. Am J Cardiol. 2013;111:1523-9.

9. Haghi D, Roehm S, Hamm K, Harder N, Suselbeck T, Borggrefe M, et al. Takotsubo cardiomyopathy is not due to plaque rupture: an intravascular ultrasound study. Clin Cardiol. 2010;33:307-10.

10. Lyon AR, Bossone E, Schneider B, Sechtem U, Citro R, Underwood SR, et al. Current state of knowledge on Takotsubo syndrome: a Position Statement from the Taskforce on Takotsubo Syndrome of the Heart Failure Association of the European Society of Cardiology. Eur J Heart Fail. 2016;18:8-27.

11. Prasad A, Lerman A, Rihal CS. Apical ballooning syndrome (Tako-Tsubo or stress cardiomyopathy): a mimic of acute myocardial infarction. Am Heart J. 2008;155:408-17.

12. Aletras AH, Tilak GS, Natanzon A, Hsu L-Y, Gonzalez FM, Hoyt RF, et al. Retrospective determination of the area at risk for reperfused acute myocardial infarction with T2-weighted cardiac magnetic resonance imaging: histopathological and displacement encoding with stimulated echoes (DENSE) functional validations. Circulation. 2006;113:1865-70.

13. Friedrich MG, Abdel-Aty $H$, Taylor A, Schulz-Menger J, Messroghli D, Dietz R. The salvaged area at risk in reperfused acute myocardial infarction as visualized by cardiovascular magnetic resonance. J Am Coll Cardiol. 2008;51:1581-7.

14. Fuernau G, Eitel I, Franke V, Hildebrandt L, Meissner J, de Waha S, et al. Myocardium at risk in ST-segment elevation myocardial infarction comparison of T2-weighted edema imaging with the MR-assessed endocardial surface area and validation against angiographic scoring. JACC Cardiovasc Imaging. 2011;4:967-76.

15. Phrommintikul A, Abdel-Aty H, Schulz-Menger J, Friedrich MG, Taylor AJ. Acute oedema in the evaluation of microvascular reperfusion and myocardial salvage in reperfused myocardial infarction with cardiac magnetic resonance imaging. Eur J Radiol. 2010;74:e12-7.

16. Wright J, Adriaenssens T, Dymarkowski S, Desmet W, Bogaert J. Quantification of myocardial area at risk with T2-weighted CMR: comparison with contrast-enhanced CMR and coronary angiography. JACC CardiovasC Imaging. 2009;2:825-31

17. Schulz-Menger J, Bluemke DA, Bremerich J, Flamm SD, Fogel MA, Friedrich $M G$, et al. Standardized image interpretation and post processing in cardiovascular magnetic resonance: Society for Cardiovascular Magnetic Resonance (SCMR) board of trustees task force on standardized post processing. J Cardiovasc Magn Reson. 2013;15:35.

18. Kurisu S, Inoue I, Kawagoe T, Ishihara M, Shimatani Y, Nakama Y, et al. Presentation of Tako-tsubo cardiomyopathy in men and women. Clin Cardiol. 2010:33:42-5.

19. Schneider B, Athanasiadis A, Stöllberger C, Pistner W, Schwab J, Gottwald U, et al. Gender differences in the manifestation of tako-tsubo cardiomyopathy. Int J Cardiol. 2013;166:584-8.

20. Le Ven F, Pennec P-Y, Timsit S, Blanc J-J. Takotsubo syndrome associated with seizures: an underestimated cause of sudden death in epilepsy? Int J Cardiol. 2011;146:475-9.

21. Summers MR, Lennon RJ, Prasad A. Pre-morbid psychiatric and cardiovascular diseases in apical ballooning syndrome (tako-tsubo/stressinduced cardiomyopathy): potential pre-disposing factors? J Am Coll Cardiol. 2010;55:700-1.

22. Naegele M, Flammer AJ, Enseleit F, Roas S, Frank M, Hirt A, et al. Endothelial function and sympathetic nervous system activity in patients with Takotsubo syndrome. Int J Cardiol. 2016;224:226-30.

23. Redfors $B$, Vedad R, Angerås $O$, Råmunddal T, Petursson P, Haraldsson I, et al. Mortality in takotsubo syndrome is similar to mortality in myocardial infarction - A report from the SWEDEHEART registry. Int J Cardiol. 2015;185:282-9.

24. Herath HMMTB, Pahalagamage SP, Lindsay LC, Vinothan S, Withanawasam S, Senarathne $V$, et al. Takotsubo cardiomyopathy complicated with apical thrombus formation on first day of the illness: a case report and literature review. BMC Cardiovasc Disord. 2017;17:176. 
25. Kyuma M, Tsuchihashi K, Shinshi Y, Hase M, Nakata T, Ooiwa H, et al. Effect of intravenous propranolol on left ventricular apical ballooning without coronary artery stenosis (ampulla cardiomyopathy): three cases. Circ J. 2002;66:1181-4.

26. Santoro F, leva R, Ferraretti A, Fanelli M, Musaico F, Tarantino N, et al. Hemodynamic effects, safety, and feasibility of intravenous esmolol infusion during Takotsubo cardiomyopathy with left ventricular outflow tract obstruction: results from a multicenter registry. Cardiovasc Ther. 2016;34:161-6.

27. Yoshioka T, Hashimoto A, Tsuchihashi K, Nagao K, Kyuma M, Ooiwa H, et al. Clinical implications of midventricular obstruction and intravenous propranolol use in transient left ventricular apical ballooning (Tako-tsubo cardiomyopathy). Am Heart J. 2008;155:526.e1-7.

28. Ozaki K, Okubo T, Tanaka K, Hosaka Y, Tsuchida K, Takahashi K, et al. Manifestation of latent left ventricular outflow tract obstruction in the acute phase of Takotsubo cardiomyopathy. Intern Med Tokyo Jpn. 2016;55:3413-20.

29. Izumi Y, Okatani H, Shiota M, Nakao T, Ise R, Kito G, et al. Effects of metoprolol on epinephrine-induced takotsubo-like left ventricular dysfunction in non-human primates. Hypertens Res. 2009;32:339-46.

30. Paur H, Wright PT, Sikkel MB, Tranter MH, Mansfield C, O'Gara P, et al. High levels of circulating epinephrine trigger apical cardiodepression in a $\beta 2-$ adrenergic receptor/Gi-dependent manner: a new model of Takotsubo cardiomyopathy. Circulation. 2012;126:697-706.

31. Singh K, Carson K, Usmani Z, Sawhney G, Shah R, Horowitz J. Systematic review and meta-analysis of incidence and correlates of recurrence of takotsubo cardiomyopathy. Int J Cardiol. 2014;174:696-701.

32. Elesber AA, Prasad A, Lennon RJ, Wright RS, Lerman A, Rihal CS. Four-year recurrence rate and prognosis of the apical ballooning syndrome. J Am Coll Cardiol. 2007:50:448-52.

33. Ahtarovski KA, Iversen KK, Christensen TE, Andersson H, Grande P, Holmvang L, et al. Takotsubo cardiomyopathy, a two-stage recovery of left ventricular systolic and diastolic function as determined by cardiac magnetic resonance imaging. Eur Heart J Cardiovasc Imaging. 2014;15:855-62.

34. Kumar S, Waldenborg M, Bhumireddy P, Ramkissoon K, Loiske K, Innasimuthu $\mathrm{AL}$, et al. Diastolic function improves after resolution of takotsubo cardiomyopathy. Clin Physiol Funct Imaging. 2016;36:17-24

35. Meimoun P, Abouth S, Boulanger J, Luycx-Bore A, Martis S, Clerc J. Relationship between acute strain pattern and recovery in tako-tsubo cardiomyopathy and acute anterior myocardial infarction: a comparative study using two-dimensional longitudinal strain. Int J Cardiovasc Imaging. 2014:30:1491-500.

\section{Submit your next manuscript to BioMed Central and we will help you at every step:}

- We accept pre-submission inquiries

- Our selector tool helps you to find the most relevant journal

- We provide round the clock customer support

- Convenient online submission

- Thorough peer review

- Inclusion in PubMed and all major indexing services

- Maximum visibility for your research

Submit your manuscript at www.biomedcentral.com/submit

CBiomed Central 